\title{
OVERVIEW
}

\section{Mycobacteria research in the post-genomic era}

\author{
Douglas B. Young \\ Tel: +44 207594 3962. Fax: +44 207594 3095. e-mail: d.young@ic.ac.uk
}

Centre for Molecular Microbiology and Infection, Department of Infectious Diseases and Microbiology, Faculty of Medicine, Imperial College of Science, Technology and Medicine, London SW7 2AZ, UK

Keywords: cell wall, lipids, drug targets, immune response.

\section{Background}

The last decade has witnessed renewed concern about the impact of tuberculosis on global health against a background of synergy with HIV, the emergence of drug-resistant strains and well-publicized outbreaks in the USA and Europe. In contrast, successful implementation of multidrug therapy has fostered complacency about leprosy as a threat to public health, even though the number of new cases remains disturbingly high in the most prevalent areas (Lockwood, 2002). Interest has been maintained in the opportunistic 'atypical' mycobacteria, in relation to their ability to cause disease in immunocompromised individuals and, increasingly, their possible role in modifying immune responses to the major pathogenic species (Brandt et al., 2002). Rapidgrowing non-pathogenic mycobacteria have had an important role as model organisms in the study of fundamental aspects of microbiology.

Over the same period, there has been a renaissance in microbiological interest in the mycobacterial genus with the introduction of new molecular genetic tools. The slow growth rate and rugged cell wall structure make mycobacteria - particularly the major pathogens - difficult targets for classical genetics and biochemistry. These barriers are substantially overcome by approaches based on dissection of mycobacteria at the level of DNA, however, and the present special issue of Microbiology celebrates the wealth of current interest in research on the mycobacterial genus in the post-genomic era.

\section{The mycobacteria special issue}

Much of modern mycobacteriology is conducted within the framework provided by the genome sequence, and the special issue is introduced by a review article from Cole that presents a definitive description of the application of genomics to our current understanding of the M. tuberculosis complex (Cole, 2002). A useful update on the genome annotation of $M$. tuberculosis $\mathrm{H} 37 \mathrm{Rv}$ is provided in a paper by Camus et al. (2002). Genome comparison amongst different isolates and between species plays an important role in understanding the epidemiology and evolution of the mycobacteria, and papers by Dullaghan and by Howard contribute to this area, describing a novel two-dimensional electrophoresis genotyping system (Dullaghan et al., 2002) and a mobile genetic element from Mycobacterium abscessus, a rapid-growing opportunistic pathogen (Howard et al., 2002). There is clearly important scope for linking this genotypic diversity to phenotypic variations such as the differences in cell wall mycolic acid structures used by Astola et al. (2002) to discriminate between strains of Mycobacterium gordonae.

Several papers take up the challenge of moving from genome sequence to functional biology. McAdam et al. (2002) describe mapping of insertion points in a transposon library of Mycobacterium tuberculosis, identifying mutations affecting more than 350 individual ORFs. In addition to providing 'off-the-shelf' mutants available for researchers with an interest in these particular genes, this study begins to define the set of M. tuberculosis genes that are dispensable for growth in laboratory media. An important aspect of the study is that it highlights a bias in the pattern of Tn5370 insertion events, with predominant targeting of regions with lower than average $\mathrm{G}+\mathrm{C}$ content. Mutagenesis by allele replacement is illustrated in two papers. Bardarov et al. (2002) describe a novel technique for the introduction of targeted mutations using a temperature-sensitive transducing phage, while Parish \& Stoker (2002) focus on analysis of genes that are essential for in vitro growth, specifically those involved in the chorismate pathway for aromatic amino acid biosynthesis.

There is considerable interest in understanding mechanisms involved in the regulation of gene expression in mycobacteria. Santangelo et al. (2002) have analysed the expression of genes implicated in entry into mammalian host cells (the mce operon) and report on a novel transcriptional regulator. Stewart and colleagues describe the use of microarray-based whole genome expression profiling to explore the adaptation of M. tuberculosis to environmental changes. Focusing on the response to heat shock, they have identified a series 
of overlapping regulatory circuits involving alternative sigma factors and two heat shock-specific transcriptional repressors (Stewart et al., 2002). As in the case of the oxidative response genes described by Master et al. (2002), stress-induced changes in mycobacteria are likely to be important in survival during infection and as signals for the host immune defence (Stewart et al., 2001).

Analysis of the structure of mycobacterial cell wall components has provided a consistent topic for outstanding biological chemistry; increasingly this is achieved in tandem with a molecular genetic approach. Kremer et al. (2002) demonstrate that, in addition to the heat-shock proteins discussed above, changes in cell wall lipids are also a feature of the adaptive response to temperature stress. It is probable that remodelling of the cell wall will be an important component in the physiology of mycobacterial infection, and Ohja et al. (2002) describe a novel polar glycopeptidolipid synthesized by $M$. smegmatis grown in glucose-limited culture. Papers from Etienne et al. and from Jeevarajah et al. make use of molecular genetic tools to study the biosynthesis of glycopeptidolipids in Mycobacterium smegmatis (Jeevarajah et al., 2002), and to demonstrate the important role that they play in determining surface properties and permeability (Etienne et al., 2002). Hancock et al. (2002) provide further information about the assembly of arabinogalactan and peptidoglycan, a central step in construction of the mycobacterial cell wall. Two papers report investigation of lipoarabinomannan, a cell wall component shown to be crucial in triggering responses in the infected host. Kaur et al. (2002) provide a detailed description of arabinose motifs involved in antibody binding to lipoarabinomannan and arabinogalactan, and Ludwiczak and colleagues report an alteration in the fine structure of lipoarabinomannan in a phoP knock out mutant of $M$. tuberculosis (Ludwiczak et al., 2002). The phoP gene encodes part of a two-component response regulator and the knock out strain is attenuated in a mouse model (Perez et al., 2001). It is not clear whether the altered lipoarabinomannan structure is a direct or a secondary effect of the mutation. Garton and colleagues report that lipids are involved not only in the cell wall structure, but also in intracellular storage depots. They observed lipophilic inclusions in $M$. smegmatis cultures grown in vitro, and also in M. tuberculosis in sputum (Garton et al., 2002), adding to the growing body of evidence that lipids are an essential source of nutrition for M. tuberculosis within the infected host (McKinney et al., 2000).

An important goal of current research is to identify targets for new drugs. McLean et al. (2002) describe the potential for exploitation of the multiple cytochrome P450 homologues in M. tuberculosis as drug targets, and Douglas et al. (2002) report on promising antimycobacterial activity of thiolactomycin derivatives. Turner and colleagues used molecular genetic tools to construct luminescent reporter strains of mycobacteria suitable for rapid assessment of drug action. Carrying out experiments with infected tissues, they stress the im- portance of interactions between drugs and host immunity, highlighting synergy between pyrazinamide and early events in the cell-mediated immune response (Turner et al., 2002).

Finally, a series of papers report on the immune response to mycobacterial infection. Collins et al. (2002) describe the use of mycobacterial mutants for vaccine development, while Gomes \& Appelberg (2002) have used knock out mice to demonstrate that reactive oxygen species are not required for resistance to Mycobacterium avium infection. Fattorini et al. (2002) report that low dose infection with $M$. avium has a protective effect against subsequent high dose challenge, and Gruppo et al. (2002) and DesJardin et al. (2002) highlight the important role played by cell surface adhesion molecules during M. tuberculosis infection in mice and in human macrophages.

\section{Conclusion}

This special issue provides an impressive demonstration of the very active current research on the molecular microbiology of the mycobacteria. Will this be sufficient to reverse the progressive rise in global tuberculosis? The combined advances in molecular genetics and cell wall biochemistry provide a scientific platform suitable for development of a new generation of drugs directed against the emerging multidrug-resistant strains. As with existing drugs, it is likely that these will act primarily against actively dividing organisms, and that prolonged treatment regimens will be required for a reliable cure. Prospects for the development of shorter treatments and for the rational design of effective vaccines will depend on our ability to translate successful studies of mycobacteria in the test tube and in experimental models into an improved understanding of the complex biology of mycobacteria during their prolonged residence in human tissues.

\section{References}

Astola, J., Muñoz, M., Sempere, M., Coll, P., Luquin, M. \& ValeroGuillen, P. L. (2002). The HPLC-double-cluster pattern of some Mycobacterium gordonae strains is due to their dicarboxymycolate content. Microbiology 148, 3119-3127.

Bardarov, S., Bardarov, S., Jr, Pavelka, M. S., Jr, Sambandamurthy, V., Larsen, M., Tufariello, J., Chan, J., Hatfull, G. \& Jacobs, W., Jr (2002). Specialized transduction: an efficient method for generating marked and unmarked targeted gene disruptions in Mycobacterium tuberculosis, M. bovis BCG and. M. smegmatis. Microbiology 148, 3007-3017.

Brandt, L., Feino Cunha, J., Weinreich Olsen, A., Chilima, B., Hirsch, P., Appelberg, R. \& Andersen, P. (2002). Failure of the Mycobacterium bovis BCG vaccine: some species of environmental mycobacteria block multiplication of BCG and induction of protective immunity to tuberculosis. Infect Immun 70, 672-678.

Camus, J.-C., Pryor, M. J., Médigue, C. \& Cole, S. T. (2002). Reannotation of the genome sequence of Mycobacterium tuberculosis H37Rv. Microbiology 148, 2967-2973.

Cole, S. T. (2002). Comparative and functional genomics of the Mycobacterium tuberculosis complex. Microbiology 148, 29192928. 
Collins, D. M., Wilson, T., Campbell, S., Buddle, B. M., Wards, B. J., Hotter, G. \& de Lisle, G. W. (2002). Production of avirulent mutants of Mycobacterium bovis with vaccine properties by the use of illegitimate recombination and screening of stationaryphase cultures. Microbiology 148, 3019-3027.

DesJardin, L. E., Kaufman, T. M., Potts, B., Kutzbach, B., Yi, H. \& Schlesinger, L. S. (2002). Mycobacterium tuberculosis-infected human macrophages exhibit enhanced cellular adhesion with increased expression of LFA-1 and ICAM-1 and reduced expression and/or function of complement receptors, Fc $\gamma$ RII and the mannose receptor. Microbiology 148, 3161-3171.

Douglas, J. D., Senior, S. J., Morehouse, C., Phetsukiri, B., Campbell, I. B., Besra, G. S. \& Minnikin, D. E. (2002). Analogues of thiolactomycin: potential drugs with enhanced antimycobacterial activity. Microbiology 148, 3101-3109.

Dullaghan, E. M., Malloff, C. A., Li, A. H., Lam, W. L. \& Stokes, R. W. (2002). Two-dimensional bacterial genome display: a method for the genomic analysis of mycobacteria. Microbiology 148, 3111-3117.

Etienne, G., Villeneuve, C., Billman-Jacobe, H., Astarie-Dequeker, C., Dupont, M.-A. \& Daffé, M. (2002). The impact of the absence of glycopeptidolipids on the ultrastructure, cell surface and cell wall properties, and phagocytosis of Mycobacterium smegmatis. Microbiology 148, 3089-3100.

Fattorini, L., Nisini, R., Fan, Y., Li, Y.-J., Tan, D., Mariotti, S., Teloni, R., lona, E. \& Orefici, G. (2002). Exposure of BALB/c mice to low doses of Mycobacterium avium increases resistance to a subsequent high-dose infection. Microbiology 148, 3173-3181.

Garton, N. J., Christensen, H., Minnikin, D. E., Agedbola, R. A. \& Barer, M. R. (2002). Intracellular lipophilic inclusions of mycobacteria in vitro and in sputum. Microbiology 148, 2951-2958.

Gomes, M. S. \& Appelberg, R. (2002). NRAMP1- or cytokineinduced bacteriostasis of Mycobacterium avium by mouse macrophages is independent of the respiratory burst. Microbiology 148, 3155-3160.

Gruppo, V., Turner, O. C., Orme, I. M. \& Turner, J. (2002). Reduced up-regulation of memory and adhesion/integrin molecules in susceptible mice and poor expression of immunity to pulmonary tuberculosis. Microbiology 148, 2959-2966.

Hancock, I. C., Carman, S., Besra, G. S., Brennan, P. J. \& Waite, E. (2002). Ligation of arabinogalactan to peptidoglycan in the cell wall of Mycobacterium smegmatis requires concomitant synthesis of the two wall polymers. Microbiology 148, 3059-3067.

Howard, S. T., Byrd, T. F. \& Lyons, C. R. (2002). A polymorphic region in Mycobacterium abscessus contains a novel insertion sequence element. Microbiology 148, 2987-2996.

Jeevarajah, D., Patterson, J. H., McConville, M. J. \& BillmanJacobe, H. (2002). Modification of glycopeptidolipids by an $\mathrm{O}-$ methyltransferase of Mycobacterium smegmatis. Microbiology 148, 3079-3087.

Kaur, D., Lowary, T. L., Vissa, V. D., Crick, D. C. \& Brennan, P. J. (2002). Characterization of the epitope of anti-lipoarabinoman- nan antibodies as the terminal hexaarabinofuranosyl motif of mycobacterial arabinans. Microbiology 148, 3049-3057.

Kremer, L., Guérardel, Y., Gurcha, S. S., Locht, C. \& Besra, G. S. (2002). Temperature-induced changes in the cell-wall components of Mycobacterium thermoresistibile. Microbiology 148, 31453154.

Lockwood, D. N. J. (2002). Leprosy elimination - a virtual phenomenon or a reality? BMJ 324, 1516-1518.

Ludwiczak, P., Gilleron, M., Bordas, Y., Martin, C., Gicquel, B. \& Puzo, G. (2002). Mycobacterium tuberculosis phoP mutant: lipoarabinomannan molecular structure. Microbiology 148, 3029-3037.

Master, S. S., Springer, B., Sander, P., Boettger, E. C., Deretic, V. \& Timmins, G. S. (2002). Oxidative stress response genes in Mycobacterium tuberculosis: role of ahpC in resistance to peroxynitrite and stage-specific survival in macrophages. Microbiology 148, 3139-3144.

McAdam, R. A., Quan, S., Smith, D. A. \& 11 other authors (2002). Characterization of a Mycobacterium tuberculosis H37Rv transposon library reveals insertions in 351 ORFs and mutants with altered virulence. Microbiology 148, 2975-2986.

McKinney, J. D., Honer zu Bentrup, K., Munoz-Elias, E. J. \& 7 other authors (2000). Persistence of Mycobacterium tuberculosis in macrophages and mice requires the glyoxylate shunt enzyme isocitrate lyase. Nature 406, 735-738.

McLean, K. J., Marshall, K. R., Richmond, A., Hunter, I. S., Fowler, K., Kieser, T., Gurcha, S. S., Besra, G. S. \& Munro, A. W. (2002). Azole antifungals are potent inhibitors of cytochrome P450 mono-oxygenases and bacterial growth in mycobacteria and streptomycetes. Microbiology 148, 2937-2949.

Ojha, A. Kr., Varma, S. \& Chatterji, D. (2002). Synthesis of an unusual polar glycopeptidolipid in glucose-limited culture of Mycobacterium smegmatis. Microbiology 148, 3039-3048.

Parish, T. \& Stoker, N. G. (2002). The common aromatic amino acid biosynthesis pathway is essential in Mycobacterium tuberculosis. Microbiology 148, 3069-3077.

Perez, E., Samper, S., Bordas, Y., Guilhot, C., Gicquel, B. \& Martin, C. (2001). An essential role for phoP in Mycobacterium tuberculosis virulence. Mol Microbiol 41, 179-187.

Santangelo, M. P., Goldstein, J., Alito, A. \& 7 other authors (2002). Negative transcriptional regulation of the mce 3 operon in Mycobacterium tuberculosis. Microbiology 148, 2997-3006.

Stewart, G. R., Snewin, V. A., Walzl, G. \& 7 other authors (2001). Overexpression of heat shock proteins reduces survival of Mycobacterium tuberculosis in the chronic phase of infection. Nat Med 7, 732-737.

Stewart, G. R., Wernisch, L., Stabler, R., Mangan, J. A., Hinds, J., Laing, K. G., Young, D. B. \& Butcher, P. D. (2002). Dissection of the heat-shock response in Mycobacterium tuberculosis using mutants and microarrays. Microbiology 148, 3129-3138.

Turner, D. J., Hoyle, S. L., Snewin, V. A., Gares, M.-P., Brown, I. N. \& Young, D. B. (2002). An ex vivo culture model for screening drug activity against in vivo phenotypes of Mycobacterium tuberculosis. Microbiology 148, 2929-2936. 